\title{
A Case of Pituitary Insufficiency in a Patient Presenting with Hyponatremia: Might Be Slow-Progressing Lymphocytic Hypophysitis as a Possible Cause of Empty Sella?
}

Gülşah Elbüken ${ }^{1}$ (D) Ece Baydar², (D) Sonat Pınar Kara ${ }^{2}$ (D)

${ }^{1}$ Namik Kemal University, Faculty of Medicine, Department of Endocrinology and Metabolism, Tekirdag, Turkey

${ }^{2}$ Namik Kemal University, Faculty of Medicine, Department of Internal Medicine, Tekirdag, Turkey

\begin{abstract}
Pituitary insufficiency is a clinical condition arising from the deficiency of one or more of the pituitary hormones. Hypophysitis generally involves lymphocytic, granulomatous, plasmacytic and xantomatous infiltration and its diagnosis requires histological confirmation. The most common cause of hypophysitis is "lymphocytic hypophysitis".

A 75-year-old female patient presented with complaints of nausea, weakness, fatigue and generalized pain all over her body. Her medical history included essential hypertension, type 2 diabetes mellitus, coronary artery disease and hypothyroidism. She was hospitalized due to detecting a serum sodium $\left(\mathrm{Na}^{+}\right)$ concentration of $123 \mathrm{mmol} / \mathrm{L}$. Although her diuretic medications were discontinued and fluid replacement with parenteral hypertonic saline infusion was instituted for approximately 6 days, $\mathrm{Na}^{+}$level did not return to normal. Secondary hypothyroidism was considered due to laboratory test results showing low $\mathrm{fT}_{4}$ level and markedly suppressed TSH value. Since further laboratory workup showed that TSH, ACTH, PRL, GH and gonadotropins were also low, the diagnosis was confirmed as "panhypopituitarism". Her obstetric history was not suggestive of Sheehan's Syndrome and she did not have a history of head injury or cerebrovascular disease. She was started on parenteral $100 \mathrm{mg}$ hydrocortisone and hormonal replacement therapy with oral levothyroxine. The clinical picture of the patient improved dramatically with resolution of hyponatremia.

Lymphocytic hypophysitis is an autoimmune disorder of the pituitary gland and it mostly affects middleaged women. The fact that our patient was the age of 75 without having any clinical symptoms, since she had "panhypopituitarism" and a "partially empty sella" appearance in her pituitary MRI scans, "lymphocytic hypophysitis" was considered as the probably cause of pituitary insufficiency even if her age was older than the typical age of patients affected by the condition. It suggests that slow-progressing primary hypophysitis (probably lymphocytic hypophysitis) can lead to pituitary insufficiency at a later age.
\end{abstract}

Turk J Int Med 2020;2(2):51-55 DOI: $10.46310 /$ tjim. 714043

Keywords: Hyponatremia, pituitary insufficiency, lymphocytic hypophysitis.

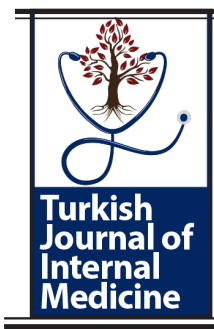

Received:April 06,2020;Accepted:April 26,2020; Published Online:April 29,2020

Namik Kemal University, Faculty of Medicine, Department of Endocrinology and Metabolism, Tekirdag, 59030, Turkey

E-mail:gelbuken@nku.edu.tr 


\section{Introduction}

Hyponatremia, defined as a serum $\mathrm{Na}^{+}$ $\left(\mathrm{Na}^{+}\right)$concentration less than $135 \mathrm{mmol} / \mathrm{L}$, is the most common type of electrolyte disturbance. The biochemical finding of a serum $\mathrm{Na}^{+}$concentration between 130-135 mmol/L as measured by an ion specific electrode is classified as "mild" hyponatremia, a serum sodium concentration between 125-129 $\mathrm{mmol} / \mathrm{L}$ as "moderate" hyponatremia and a serum sodium concentration less than $125 \mathrm{mmol} / \mathrm{L}$ as "profound" hyponatremia". Severe hyponatremia is a potentially life-threatening condition and a significant cause of morbidity and mortality. Mild-to-moderate hyponatremia (a $\mathrm{Na}^{+}$value ranging from 125 to 135 $\mathrm{mmol} / \mathrm{L}$ ) is known to have a significant effect on cognitive function, particularly in older patients. Hyponatremia can also be classified based on time of development and 'acute' hyponatremia is defined as hyponatremia that is documented to exist $<48$ hours and 'chronic' hyponatremia as hyponatremia that is documented to exist for at least 48 hours. It is crucial to determine whether hyponatremia has developed acutely or had been present on a chronic basis and identify the underlying etiology of hyponatremia in order to provide corrective therapy. It is equally important to establish whether the patient is "hypovolemic", "hypervolemic" or "euvolemic" on the basis of physical examination findings. ${ }^{1,2}$

Euvolemic hyponatremia can develop as a result of glucocorticoid deficiency, the syndrome of inappropriate antidiuresis (SIAD), hypothyroidism, stress and medications and the urinary $\mathrm{Na}^{+}$level is greater than $20 \mathrm{mmol} / \mathrm{L} \cdot{ }^{1-3}$ Other causes should be excluded in order to make a diagnosis of SIAD. ${ }^{3,4}$ Glucocorticoid deficiency can be caused by primary or secondary adrenal insufficiency. Secondary adrenal insufficiency occurs when the adrenal cortex fails to produce adequate amounts of glucocorticoids as a result of insufficient adrenocorticotropic hormone (ACTH) secretion from the pituitary gland. ACTH deficiency may occur alone or in combination with deficiencies of other pituitary hormones. ${ }^{5}$ Hypothalamic hormone deficiencies may also cause pituitary insufficiency due to absent stimulation of pituitary hormone secretion. Pituitary insufficiency is a clinical condition arising from the deficiency of one or more of the pituitary hormones. Pituitary hormone deficiency is associated with several morbidities that affect patient quality of life adversely and can even cause mortality. Many conditions can lead to pituitary insufficiency. Primary pituitary deficiency, traumatic brain injury, pituitary adenomas, pituitary surgery, infiltrative disorders that involve the pituitary gland or other organ tumors metastasizing to the pituitary gland may cause hypopituitarism. ${ }^{6}$ Another cause of primary pituitary insufficiency is "hypophysitis" which is the inflammation of the pituitary gland that occurs due to various reasons. Hypophysitis generally involves lymphocytic, granulomatous, plasmacytic and xantomatous infiltration and its diagnosis requires histological confirmation. The most common cause of hypophysitis is "lymphocytic hypophysitis". Patients with lymphocytic hypophysitis test positive for antipituitary antibodies. The gold standard method for the diagnosis of lymphocytic hypophysitis involves identification of the histopathology by "pituitary gland biopsy". However, the diagnosis usually is established by clinical findings and demonstration of pituitary hormone deficiencies. The diagnosis is supported when there is a deficiency of one or more of the pituitary hormones. ${ }^{6,7}$ Pituitary MRI scan shows a partially or completely empty Sella during the later stages of lymphocytichypophysitis. ${ }^{8-10}$

\section{Case Report}

A 75-year-old female patient presented to the emergency room with complaints of nausea, weakness, fatigue and generalized pain all over her body. Her medical history included essential hypertension, type 2 diabetes mellitus (DM), coronary artery disease and hypothyroidism and was being followed at the Internal Medicine outpatient clinic of our hospital. Her current treatment included a combination of irbesartan and hydrochlorothiazide, indapamide, metformin, gliclazide, isosorbide monohydrate, acetyl salicylic acid and levothyroxine.

Medical History: The patient had hypertension for about 20 years and type 2 DM for 15 years. Her current treatment included a combination of irbesartan and hydrochlorothiazide, indapamide, metformin, gliclazide, isosorbide monohydrate and acetyl salicylic acid. She has been receiving levothyroxine at a dose of $100 \mathrm{mcg} / \mathrm{day}$ since a thyroid surgery that she underwent almost 25 years ago. A TSH test was requested by the Internal Medicine outpatient clinic about 6 months ago which showed TSH suppression (possibly due to secondary hypothyroidism), resulting in lowering of the levothyroxine dose to $75 \mathrm{mcg} / \mathrm{day}$.

The patient had a daughter who was 52 years old at the time of her presentation and she did not report 
any problems during her pregnancy or complications at childbirth. She had breastfed her daughter. She had regular menses after the delivery and entered menopause at 50 years of age. She did not report a history of a trauma to the head or cerebrovascular disease.

Physical Examination: Her general condition was moderate, and she was in a confused state. Her arterial blood pressure was 100/60 $\mathrm{mmHg}$ and heart rate was 99 beats per minute. There were no findings of marked dehydration or hypervolemia.

Clinical Course: The patient was admitted to the Internal Medicine department upon detecting a serum sodium $\left(\mathrm{Na}^{+}\right)$concentration of $123 \mathrm{mmol} / \mathrm{L}$ obtained at the emergency room. Her diuretic medications were discontinued, and parenteral saline infusion was initiated. Serum $\mathrm{Na}^{+}$levels measured at about 6 months and 1 year prior to her admission were in normal limits as documented in her previous laboratory data stored in our hospital's archives (Table 1).

Table1. Laboratory values of the patient

\begin{tabular}{|c|c|c|c|c|c|c|}
\hline Parameters & $\begin{array}{c}\text { At } 1 \text { year } \\
\text { prior to } \\
\text { admissio } \\
n \\
\end{array}$ & $\begin{array}{c}\text { At } 6 \text { months } \\
\text { prior to } \\
\text { admission }\end{array}$ & $\begin{array}{c}\text { On } \\
\text { admission }\end{array}$ & $\begin{array}{l}\text { Before } \\
\text { starting } \\
\text { steroids }\end{array}$ & $\begin{array}{c}1 \text { day } \\
\text { after starting } \\
\text { steroids }\end{array}$ & $\begin{array}{l}\text { On final } \\
\text { follow-up }\end{array}$ \\
\hline Hb (g/dL) & 12.2 & 11.68 & 12.22 & 11.41 & 12.21 & 12.28 \\
\hline Het $(\%)$ & 38.7 & 35.1 & 35.3 & 34.6 & 36.6 & 37.6 \\
\hline WBC (uL) & 6300 & 7480 & 4670 & 5170 & 8780 & 7300 \\
\hline Platelet $\left(10^{3} / \mathrm{uL}\right)$ & 197 & 229 & 288 & 298 & 335 & 221 \\
\hline MCV (FL) & 93 & 92 & 94 & 92 & 93 & 93 \\
\hline Glucose (mg/dL) & 128 & 125 & 225 & 102 & 264 & 181 \\
\hline Urea $(\mathrm{mg} / \mathrm{dL})$ & 43 & 37 & 20 & 23 & 22 & 51 \\
\hline Creatinine (mg/dL) & 0.86 & 0.82 & 0.65 & 0.81 & 0.83 & 0.93 \\
\hline $\mathbf{N a}(\mathrm{mmol} / \mathrm{L})$ & 138 & 141 & 125 & 124 & 130 & 141 \\
\hline $\mathbf{K}(\mathrm{mmol} / \mathrm{L})$ & 4.83 & 5.07 & 4.1 & 4.38 & 5.0 & 4.64 \\
\hline $\mathbf{C l}(\mathrm{mmol} / \mathrm{L})$ & - & - & 88.8 & 94.9 & 98.2 & - \\
\hline $\mathbf{C a}(\mathrm{mg} / \mathrm{dL})$ & - & - & 8.9 & 8.3 & 8.9 & - \\
\hline $\mathbf{P}(\mathrm{mg} / \mathrm{dL})$ & - & - & 3.6 & 2.9 & 2.5 & - \\
\hline AST (IU/L) & 15 & 16 & 22 & 23 & 33 & 11 \\
\hline ALT (IU/L) & 13 & 12 & 17 & 11 & 12 & 11 \\
\hline
\end{tabular}

$\mathrm{Hb}=$ hemoglobin, $\mathrm{Hct}=$ hematocrit, $\mathrm{WBC}=$ white blood cells, $\mathrm{MCV}=$ mean corpuscular volume, $\mathrm{Na}=\mathrm{Sodium}, \mathrm{K}=$ Potassium, $\mathrm{Ca}=$ Calcium, $\mathrm{P}=$ Phosphorus, $\mathrm{AST}=$ Aspartate aminotransferase, $\mathrm{ALT}=$ alanine aminotransferase

Table 2. Hormone values of the patient

\begin{tabular}{lcccc}
\hline Parameters & $\begin{array}{c}\text { At 1 year } \\
\text { prior to admission }\end{array}$ & $\begin{array}{c}\text { At 6 months } \\
\text { prior to admission }\end{array}$ & On admission & $\begin{array}{c}\text { On final } \\
\text { follow-up }\end{array}$ \\
\hline fT3 $(\mathrm{pg} / \mathrm{ml})$ & - & $\cdot$ & 1.82 & - \\
fT4 $(\mathrm{ng} / \mathrm{dL})$ & 1.39 & 1.50 & 0.916 & 1.09 \\
TSH $(\mathrm{mIU} / \mathrm{L})$ & 0.215 & 0.369 & $<0,005$ & - \\
Anti-TPO $(\mathrm{IU} / \mathrm{mL})$ & - & - & 21.69 & - \\
Anti-TG $(\mathrm{IU} / \mathrm{mL})$ & - & - & 24.42 & - \\
Cortisol $(\mathrm{ug} / \mathrm{dL})$ & - & - & 1.76 & - \\
ACTH $(\mathrm{pg} / \mathrm{ml})$ & - & - & 3.15 & - \\
FSH $(\mathrm{mIU} / \mathrm{mL})$ & - & - & 7.5 & - \\
LH $(\mathrm{mIU} / \mathrm{mL})$ & - & - & 2.75 \\
E2 $(\mathrm{pg} / \mathrm{mL})$ & - & - & 5 & - \\
PRL $(\mathrm{ng} / \mathrm{mL})$ & - & - & 8.3 \\
IGF-1 $(\mathrm{ng} / \mathrm{mL})$ & - & - & 39.6
\end{tabular}

$\mathrm{fT} 3=$ free $\mathrm{T} 3, \mathrm{fT} 4=$ free T4, TSH= Thyroid stimulating hormone, Anti-TPO= Anti-thyroid peroxidase, Anti-TG= Antithyroglobuline, $\mathrm{ACTH}=$ adrenocorticothyropine hormone, $\mathrm{FSH}=$ Follicle stimulating hormone, $\mathrm{LH}=\mathrm{Luteinizing}$ hormone, $\mathrm{E} 2=$ estradiole, $\mathrm{PRL}=$ prolactine, $\mathrm{IGF}-1=$ insulin like growth factor-1 


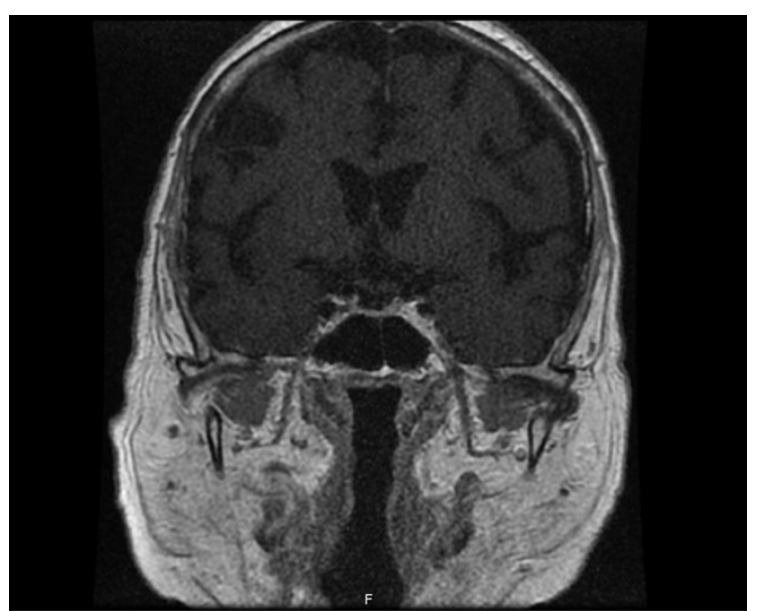

Figure 1a. Coronal section of the pituitary gland on pituitary MRI scan.

A TSH test requested by the Internal Medicine outpatient clinic about 6 months ago showed suppressed $\mathrm{TSH}$, resulting in lowering of the levothyroxine dose to $75 \mathrm{mcg} /$ day from $100 \mathrm{mcg} /$ day (Table 2).

No other laboratory tests were performed after her follow-up 6 months ago until her presentation to the emergency room with hyponatremia.

Although the patient's diuretic medications were discontinued and fluid replacement with parenteral hypertonic saline infusion was instituted for approximately 6 days, $\mathrm{Na}^{+}$level did not return to normal and thus, the patient was evaluated for the underlying reasons of hyponatremia. Secondary hypothyroidism was considered due to laboratory test results showing low fT4 level and markedly suppressed TSH value, which led to measurement of baseline plasma cortisol (BC) level to investigate secondary adrenal insufficiency. Subsequently, the patient was diagnosed with pituitary insufficiency based on a BC level of $1.75 \mu \mathrm{g} / \mathrm{dL}$. Since TSH, ACTH, PRL, $\mathrm{GH}$ and gonadotropins were also low, the diagnosis was confirmed as "panhypopituitarism". The images obtained with a pituitary MRI scan were consistent with "empty sella" (Figures 1a and 1b).

Testing for anti-pituitary antibodies could not be obtained as this is not routinely performed at our hospital laboratory. The images from a pituitary MRI scan were consistent with "empty sella" appearance. Initially, the patient was started on parenteral $100 \mathrm{mg}$ hydrocortisone and hormonal replacement therapy with oral levothyroxine. The clinical picture of the patient improved dramatically with resolution of hyponatremia. She was discharged on oral hydrocortisone and levothyroxine replacement.

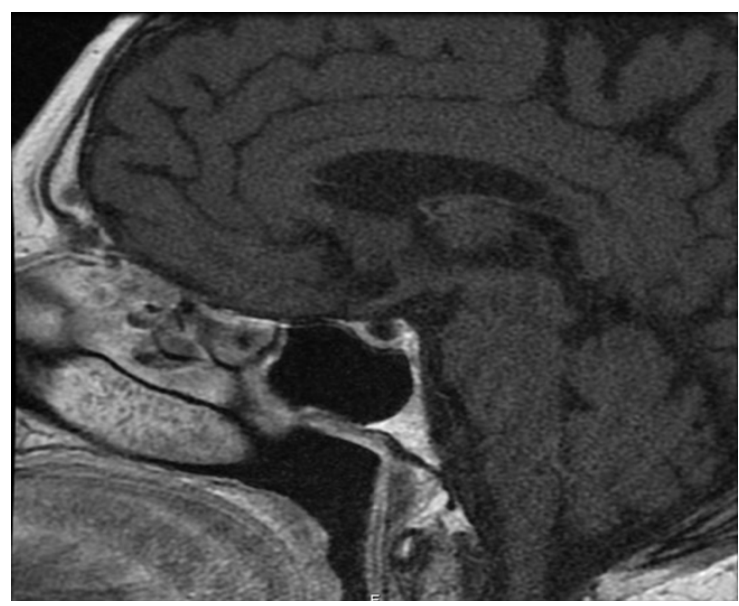

Figure 1b. Sagittal section of the pituitary gland on pituitary MRI scan.

\section{Discussion}

As suggested by the medical history of the patient, she had manifestations of slow progressing panhypopituitarism which led to her presentation to the emergency room with symptoms of hyponatremia. "Pituitary insufficiency" was suspected due to refractory hyponatremia and persistently low TSH values suggestive of secondary hypothyroidism during her hospitalization at the ICU, leading to a final diagnosis of pituitary insufficiency. In this patient, cortisol deficiency due to ACTH insufficiency was treated with steroid replacement and her clinical symptoms and hyponatremia improved dramatically post-treatment. Since our patient did not have a history of traumatic brain injury, pituitary adenomas, pituitary surgery, infiltrative disorders that involve the pituitary gland, other organ tumors metastasizing to the pituitary gland or Sheehan's syndrome that could explain pituitary insufficiency, "primary hypophysitis" was considered as the cause of pituitary insufficiency. 6,7 "Lymphocytic hypophysitis" has been reported as a cause of primary hypophysitis that results in chronic and slow-progressing pituitary insufficiency. Lymphocytic hypophysitis is an autoimmune disorder of the pituitary gland and it mostly affects middleaged women. Over time, pituitary insufficiency ensues due to lymphocytic hypophysitis and appearance of partially or completely empty Sella can be demonstrated by pituitary MRI scans. ${ }^{8-11}$ However, manifestations of "panhypopituitarism" were evident in our patient at an advanced age. Since she had "panhypopituitarism" and a "partially empty sella" appearance in her pituitary MRI scans, "primary hypophysitis (probably lymphocytic hypophysitis)" 
was considered as the cause of pituitary insufficiency even if her age was older than the typical age of patients affected by the condition. The fact that our patient could reach the age of 75 without having any clinical symptoms of the disease suggests that primary hypophysitis (probably lymphocytic hypophysitis) can lead to pituitary insufficiency at a later age with a slow progressive course.

As patients with secondary hypothyroidism have a decreased secretion of TSH because of pituitary insufficiency, the dosage should be adjusted taking into account the $\mathrm{fT}_{4}$ level during levothyroxine replacement therapy. Growth hormone replacement therapy was not given to our patient since she was at an advanced age and her clinical condition improved considerably with the treatments provided. The patient was discharged with routine clinical follow-up care.

\section{Conclusion}

Lymphocytic hypophysitis mostly affects middle-aged women. However, manifestations of "panhypopituitarism" were evident in our patient at an older age. It suggests that slow-progressing primary hypophysitis (probably lymphocytic hypophysitis) can lead to pituitary insufficiency at a later age.

\section{Acknowledgements:}

This case was partly reported as a poster presentation at 41st Congress of Endocrinology and Metabolism held between April, 27 - May 1, 2019, Antalya, Turkey.

\section{Conflict of interest}

The authors declared that there are no potential conflicts of interest with respect to the research, authorship, and/or publication of this article.

\section{References}

1. Sterns RH. Disorders of plasmasodium-causes, consequences, and correction. N Engl J Med . 2015 Jan 1;372(1):55-65. doi: 10.1056/NEJMra1404489.

2. Spasovski G, Vanholder R, Allolio B, Annane D, Ball S, Bichet D, Decaux G, Fenske W, Hoorn EJ, Ichai C, Joannidis M, Soupart A, Zietse R, Haller M, van der Veer S, Van Biesen W, Nagler E; Hyponatraemia Guideline Development Group. Clinical practice guideline on diagnosis and treatment of hyponatraemia. Nephrol Dial Transplant. 2014 Apr;29 Suppl 2:i1-i39. doi: 10.1093/ndt/ gfu040.

3. Grant P, Ayuk J, Bouloux PM, Cohen M, Cranston I, Murray $\mathrm{RD}$, Rees A, Thatcher N, Grossman A. The diagnosis and management of inpatient hyponatraemia and SIADH. Eur J Clin Invest. 2015 Aug;45(8):888-94. doi: 10.1111/eci.12465.

4. Cuesta M, Thompson CJ. The syndrome of inappropriate antidiuresis (SIAD). Best Pract Res Clin Endocrinol Metab. 2016 Mar;30(2):175-87. doi: 10.1016/j.beem.2016.02.009.

5. Garrahy A, Thompson CJ. Hyponatremia and Glucocorticoid Deficiency. Front Horm Res. 2019;52:80-92. doi: 10.1159/000493239.

6. Gubbi S, Hannah-Shmouni F, Stratakis CA, Koch CA. Primary hypophysitis and other autoimmune disorders of the sellar and suprasellar regions. Rev Endocr Metab Disord. 2018 Dec;19(4):335-47. doi: 10.1007/ s11154-018-9480-1.

7. Korkmaz OP, Sahin S, Ozkaya HM, Apaydin T, Durmaz ES, Haliloglu O, Durcan E, Kadioglu P. Primary hypophysitis: Experience of a Single Tertiary Center. Exp Clin Endocrinol Diabetes. 2019 Jun 24. doi: 10.1055/ a-0919-4388. [Epub ahead of print].

8. Gao H, Gu YY, Qiu MC. Autoimmune hypophysitis may eventually become empty sella. Neuro Endocrinol Lett. 2013;34(2):102-6.

9. Nishiyama S, Takano T, Hidaka Y, Takada K, Iwatani Y, Amino N. A case of postpartum hypopituitarism associated with empty sella: possible relation to postpartum autoimmune hypophysitis. Endocr J. 1993 Aug;40(4):431-8.

10. Karaca Z, Tanriverdi F, Unluhizarci K, Kelestimur F, Donmez H. Empty sella may be the final outcome in lymphocytic hypophysitis. Endocr Res. 2009;34(1-2):10-7. doi: 10.1080/07435800902841306.

11. Ishikawa S, Furuse M, Saito T, Okada K, Kuzuya T. Empty sella in control subjects and patients with hypopituitarism. Endocrinol Jpn. 1988 Oct;35(5):665-74. 